\title{
The Role of Mental Imagery in Osteopathic Palpation: A qualitative study
}

Mario M. Kraml' ${ }^{1}$ MSc D.O.; Jean-Pierre Besse D.O. ${ }^{2}$

\section{Abstract}

Background: Palpation constitutes a central element of osteopathic diagnosis and therapy. It is a complex tactile performance and as such also depends on cognitive factors. References by experienced osteopaths (EOs) suggest that the ability to visualise anatomical structures is essential during palpation. Scientific studies in this field can hardly be found. This study aimed to systematically determine what role mental imagery (MI) plays for osteopaths and especially what the benefits are when it is used spontaneously and deliberately.

Material and Methods: The present study is a qualitative study. Nine interviews with EOs were carried out with the help of an interview guideline and analysed using a qualitative analysis of content using the software MAXQDA.

Results: All EOs regarded $\mathrm{MI}$ as a tool as well as an interfering factor for palpation. Its supporting role was associated with the identification, recognition and comparing of anatomical conditions, with directing attention, with navigation and orientation. The limiting character showed up in distraction and deception by mental images. The results also revealed the situational use of $\mathrm{Ml}$ as well as different mental images and influencing factors (e.g. visualisation training).

Discussion: The study provides an insight into the application knowledge of EOs and shows some aspects of palpation, which have been subject to little research so far. Being aware of and understanding the role of $\mathrm{MI}$ as a top-down process in tactile-haptic perception should change the focus in palpation. The findings can be incorporated in daily practice as well as in the training system. To regard $\mathrm{Ml}$ as a possible bias can lead to reassessment and realignment of reliability studies. This study offers a basis for other studies to work from to explore the nature of $\mathrm{MI}$ in the tactile-haptic perception of osteopaths.

Keywords: mental imagery, palpation, osteopathy

DOI: https://doi.org/10.35740/EJOR.2019.1.1.3 


\section{Introduction}

Palpation is viewed as a stable signature feature of the professional identity and is a central element of the osteopathic training. It is regarded as a valid instrument to detect subtle structuralfunctional changes in tissue [1]. Palpation can be viewed as a complex performance of tactile-haptic perception, where both top-down and bottom-up processes are essential. Several authors call attention to the fact that it is necessary to be able to visualise anatomical structures during palpation [1-3] and point out the importance of MI in the tactile perception. MI is a subjective experience, where persons virtually "see" the objects, events or situations in their mental eye [4-5]. It is crucial in many aspects of daily life, like memory encoding and retrieval, navigation or spatial planning [6]. Research showed that MI is also of significance in the haptic perception of objects [79]. Only a few authors in the osteopathic field have scientifically examined the role of MI in palpation. Particular attention should be paid to the study of Esteves. These results suggest that through permanent clinical practice, osteopaths can process visual and tactile-haptic clues more efficiently than novices. The multimodally obtained information and the sensory integration connected with it are probably influenced by topdown processes, which are connected with visual, somesthetic and motor MI [10]. In an article Aubin, Gagnon and Morin call attention to the importance of visualising when learning and teaching palpation [11]. Esteves and Spence point out different ways to optimise the competence development in palpation. The authors refer to the close connection between MI and clinical expertise and underline the importance for students to develop detailed anatomical knowledge. This knowledge, according to the authors, supports visualising structures during palpation [12].

\section{Material and Methods}

The present study is a qualitative study. The subjective views and theories, as well as the knowledge of EOs about the object of research, were systematically gathered using interviews based on guidelines. Osteopaths with at least seven years of professional experience (postgraduate) and at least five years of experience in teaching (theoretical and practical involvement in palpation) at osteopathic teaching facilities were explicitly selected. To achieve as wide a range of perspective as possible, attention was paid to heterogeneity regarding for example period of expertise, teaching activity, gender and age. The sample size was nine osteopaths. The sampling was formed step by step (theoretical saturation).

The expert interviews were conducted orally faceto-face. The researcher took on the interviewer's role.

The interview guideline was drawn up in advance using the SPSS process and was adjusted to a small degree during the survey.

The interviews were recorded with a digital audio-recording device and subsequently transcribed word by word by an external person using the software f5. Afterwards, they were anonymised. The researcher verified the transcription.

The data were analysed using a qualitative analysis of content. The process scheme of a content-oriented approach described by Kuckartz [13] was adopted and expanded by case descriptions of all interviewees.

The complete analysis was performed using the software tools MAXQDA.

Most main categories were developed deductively, while all subcategories were developed inductively. Category definitions, key examples and coding rules were set up.

During the category-based evaluation, a summary and an analysis per category were performed, in which basic similarities and differences among the interviewees were identified.

This study was approved by the Ethics Committee at Donau-Universität Krems. 
Kraml M. M., Besse J-P. - European Journal of Osteopathic Research www.ejor.org

\begin{tabular}{|c|c|}
\hline Step & $\begin{array}{l}\text { - Selecting and recruiting an osteopathic colleague (no expert status) as well as performing } \\
\text { the test run for initial assessment }\end{array}$ \\
\hline $\begin{array}{l}\text { Ste } \\
\text { II }\end{array}$ & $\begin{array}{l}\text { - Selecting potential interviewees for test interview } \\
\text { - Recruiting by sending initial inquiry by post, including information sheet, introduction of } \\
\text { study leader, anamnesis sheet, informed consent for survey, processing and use of } \\
\text { personal data. Clarifying if interviewee has expert status and request reply. }\end{array}$ \\
\hline Step & $\begin{array}{l}\text { - In case of non-response, re-delivering the documents by post and requesting reply } \\
\text { within two weeks } \\
\text { - In case of non-response, re-delivering the documents by email and requesting reply } \\
\text { within ten days }\end{array}$ \\
\hline & - If interviewee consents, agreeing on possible date and adequate location of interview \\
\hline & $\begin{array}{l}\text { - One week before the interview: Confirming the interview date by mail and exchanging } \\
\text { of mobile phone numbers }\end{array}$ \\
\hline & $\begin{array}{l}\text { - Testing the technical functions of the recording device and making a test recording } \\
\text { - Exchanging both signed informed consent and filled-in anamnesis sheet } \\
\text { - Performing the interview in test interview mode }\end{array}$ \\
\hline & $\begin{array}{l}\text { - Completing and analyzing the Test Interview Protocol Sheet } \\
\text { - Adjusting the Interview Guideline and the questioning behavior (if necessary) } \\
\text { - Archiving the collected data }\end{array}$ \\
\hline $\begin{array}{l}\text { Step } \\
\text { VIII }\end{array}$ & $\begin{array}{l}\text { - Selecting potential interviewees for further survey phase } \\
\text { - Recruiting by sending initial inquiry by post, including information sheet, introduction of } \\
\text { study leader, anamnesis sheet, informed consent for survey, processing and use of } \\
\text { personal data. Clarifying if interviewee has expert status and request reply. }\end{array}$ \\
\hline $\begin{array}{r}\text { Ste } \\
\text { IX }\end{array}$ & - In case of non-response, proceed as defined in Step III \\
\hline & - If interviewee consents, agreeing on possible date and adequate location of interview \\
\hline $\begin{array}{c}\text { Step } \\
\text { XI }\end{array}$ & $\begin{array}{l}\text { - One week before the interview: Confirming the interview date by mail and exchanging } \\
\text { of mobile phone numbers }\end{array}$ \\
\hline $\begin{array}{l}\text { Step } \\
\text { XII }\end{array}$ & $\begin{array}{l}\text { - Testing the technical functions of the recording device and making a test recording } \\
\text { - Exchanging both signed informed consent and filled-in anamnesis sheet } \\
\text { - Performing the expert interview }\end{array}$ \\
\hline $\begin{array}{l}\text { Step } \\
\text { XIII }\end{array}$ & $\begin{array}{l}\text { - Completing and analyzing the Interview Protocol Sheet } \\
\text { - Adjusting the Interview Guideline and the questioning behavior (if necessary) } \\
\text { - Archiving the collected data }\end{array}$ \\
\hline
\end{tabular}

Figure 1. Flowchart of the survey procedure 
Kraml M. M., Besse J-P. - European Journal of Osteopathic Research www.ejor.org

\begin{tabular}{|c|c|c|c|}
\hline & \multicolumn{2}{|l|}{ Contents } & Aims and Interests \\
\hline 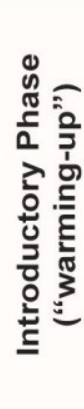 & \multicolumn{2}{|c|}{$\begin{array}{l}\text { - Warming-up conversation } \\
\text { - Thanking for being willing to take part in interview } \\
\text { - Short presentation of the study } \\
\text { - Short overview of the interview process } \\
\text { - Pointing out that the interview will be recorded } \\
\text { - Handing out the signed informed consent } \\
\text { - More Questions? }\end{array}$} & $\begin{array}{l}\text { - Creating a relaxed conversational atmo- } \\
\text { sphere } \\
\text { - Providing information to the interviewee } \\
\text { - Clear role definition } \\
\text { - Mutual exploring (e.g. interviewee's } \\
\text { speaking behavior) } \\
\text { - Clarifying and disclosure of the inter- } \\
\text { viewee's proficiency and his/her relation } \\
\text { to the topic }\end{array}$ \\
\hline \multirow{3}{*}{ 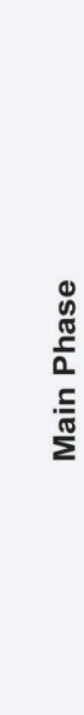 } & Topic Blocks & Dimensioning & \multirow{3}{*}{$\begin{array}{l}\text { - Gentle interview opening with the help of } \\
\text { warming-up question } \\
\text { - Defining and limiting the topic of the } \\
\text { interview } \\
\text { - Supporting questions allow for follow-up, } \\
\text { specifying and dimensioning the } \\
\text { research subject } \\
\text { - Question style: with emphasis on gentle } \\
\text { and explorative }\end{array}$} \\
\hline & $\begin{array}{l}\text { A. Super category } \\
\text { e.g. function } \\
\text { Implemented } \\
\text { in key question }\end{array}$ & $\begin{array}{l}\text { Implemented in } \\
\text { supporting questions } \\
\text { (Continuation questions } \\
\text { and specific follow-up } \\
\text { questions) }\end{array}$ & \\
\hline & $\begin{array}{l}\text { B. Super category } \\
\text { e.g. situation } \\
\text { Implemented } \\
\text { in key question }\end{array}$ & $\begin{array}{c}\text { Implemented in } \\
\text { supporting questions } \\
\text { (Continuation questions } \\
\text { and specific follow-up } \\
\text { questions) }\end{array}$ & \\
\hline 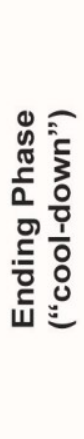 & \multicolumn{2}{|c|}{$\begin{array}{l}\text { - Thanking for participating in the interview } \\
\text { - Completing the Interview Protocol Sheet or Test } \\
\text { Interview Protocol Sheet (with corresponding } \\
\text { questions to the interviewee) } \\
\text { - Archiving interview recording, Interview Proto- } \\
\text { col Sheet or Test Interview Protocol Sheet and } \\
\text { corresponding Interview Guideline (including own } \\
\text { notes) } \\
\text { - Self-reflection, external reflection and role } \\
\text { reversal }\end{array}$} & $\begin{array}{l}\text { - Self-reflection, external reflection and } \\
\text { role reversal }\end{array}$ \\
\hline
\end{tabular}

Figure 2. Basic framework of the guideline for all expert interviews 


\section{Results}

The analysis results of the nine interviews are presented according to the drawn up category tree. This is illustrated in figure 3 :

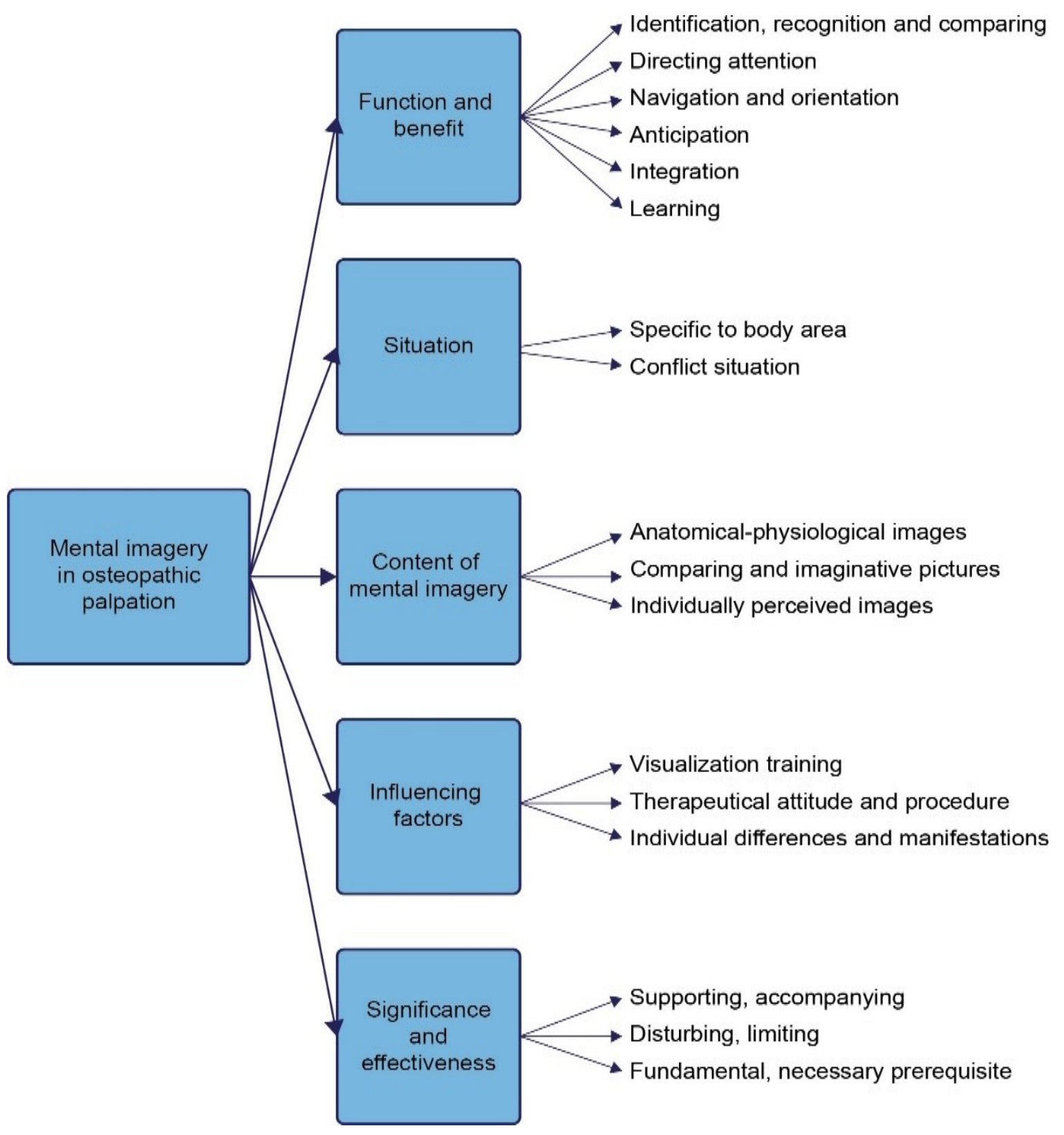

Figure 3. Overview of the research results 
The most relevant results are illustrated below.

\section{Function and Benefit}

All EOs reported that they used MI for identification, recognition and comparison during palpation. The questions "What kind of object is this (e.g. tissue, bone)?" and "What is the function of this object (e.g. movement, potential)?" are relevant to identification and recognition. Except for Interviewee2, all EOs confirmed or addressed that mental images „present themselves" (Experteninterviews $\backslash 01 \_$A: 26 - 28) during palpation. Being familiar with anatomical-physiological conditions were regarded as a prerequisite for palpation by all EOs. The ability to retrieve anatomical mental images from memory should correlate with this. It could be concluded from the overall context even though the EOs was not asked directly. Pieces of information which therapists receive through tactile-haptic detection are finally compared with existing biomedical knowledge and are the basis for further considerations. Descriptions of several EOs pointed in that direction, however in different nuances. For example, Interviewee4 regarded the ability to produce visual images as a tool to classify structures detected through palpation. Interviewee2, Interviewee6 and Interviewee8 used MI to identify anatomical structures. The ability to store tactile-haptic findings, to remember and compare them, is viewed as an essential attribute of palpation. It is regarded as the basis to adjust the diagnostic-therapeutically procedure further. This was confirmed by all EOs, who in this context also mentioned somesthetic imagery.

During palpation, osteopaths are faced with a large flood of information. In order to focus on specific body areas and ignore others, different cognitive strategies are likely to be used. The EOs largely agreed, emphasising MI as a tool for directing attention. Several Interviewees described that they use MI to distinct their own body from the patient's (see Interviewee1, Interviewee2, Interviewee3, Interviewee6 and Interviewee8).

The challenge in palpation is finding specific structures to perceive them in a tactile-haptic way. Mental images which the osteopath has already available or which he retrieves during palpation might be used as a navigation or orientation guide in this context. Statements of all EOs pointed in different degrees in this direction.

Tactile-haptic findings mainly facilitate prognoses for the future healing process and thus to adjust the palpation in particular. To what extent MI is used in this process could be extrapolated from different EOs' statements (see Interviewee1, Interviewee3, Interviewee9).

\section{Situation}

The majority of EOs indicated that they use MI in relation to the individual situation to be able to palpate deeper structures (e.g. kidneys). Interviewee7 saw no difference between surface and deep palpation. Interviewee 2 regarded it as an option only. Interviewee3 affirmed that more visualisation is necessary for the cranial area, which was also emphasised by Interviewee9.

In palpation, the therapists were often confronted with difficult situations (e.g. worries, conflicts). Accounts of several EOs pointed in the direction that in these situations visualisations are used specifically to support the palpation (see Interviewee1, Interviewee3, Interviewee5, Interviewee6).

\section{Content of MI}

All EOs pointed out the anatomical-physiological content of their mental images, even if differing in the margin, depth and specificity. The descriptions of Interviewee4, for example, showed how vital the conception of space is for palpation. The spatial aspect was taken up by all EOs, for instance, when they were talking about the topography, three-dimensionality or layering in the body. All EOs except Interviewee1 and Interviewee 2 described the use of MI with comparing or imaginative content.

\section{Influencing Factors}

According to the EOs, one factor that influences the capability to visualise is specific training even 
after the basic osteopathic training. The statements of all EOs pointed in this direction. They also showed different methods of learning (e.g. painting, see Interviewee4 and Interviewee6) and learning material (e.g. anatomy atlases, all interviewees) to optimise the process. When asked, all EOs confirmed the importance of anatomical dissection for training the visualisation capability. Also, they all agreed that the capacity to visualise anatomical structures must be linked to the tactile-haptic experience.

The attitudes and the procedures of the EOs are factors that have a determining influence on the visualisation capability. The majority of EOs said that calmness or serenity is an attribute, which facilitates MI (see Interviewee1, Interviewee3, Interviewee4, Interviewee6, and Interviewee7). Various strategies were described to achieve this (e.g. standardised behaviour, and focus, see Interviewee1). Time in the sense of "let the impression get to you" (Experteninterviews \07): 52 - 52) or "first enter into a dialogue with the patient" (see Interviewee6 and Interviewee7) is likely to be a factor to promote the visualisation process. Various EOs emphasised that it is necessary to have an open and neutral attitude in order not to respond to the patient with biased MI during the palpation and not to disturb the visualisation (see Interviewee2, Interviewee4, Interviewee6, Interviewee7).

The capability to retrieve MI depends on the particular manifestation and intensity in the visualising person. In this context, all EOs rated their visualisation capability from good to very good when asked for a self-assessment. As this question did not refer to the nervus vagus only, some EOs qualified their statement (see Interviewee3, Interviewee6) due to different levels of familiarity with anatomical structures.

\section{Significance and Effectiveness}

All EOs identify MI as a helpful and accompanying strategy for palpation. Interviewee1, Interviewee2, Interviewee3 and Interviewee5 emphasise that MI is not the aim, but a means to support the palpation. In that respect, palpation could be performed "more specific, more targeted" (see Interviewee1, Interviewee5), "reliable" (see Interviewee2), "deeper" (see Interviewee3, Interviewee4, Interviewee5), "more precise" (see Interviewee8) or "faster" (see Interviewee6, Interviewee9). According to Interviewee7, MI has a potentiating quality. In a more accurate statement, Interviewee6 pointed out that MI "[can] be taken ... as a guideline, but not as a DIRECTING factor" (Experteninterviews $\backslash 06 \_C: 13$ - 16).

When asked if the mental image of a joint that already exists in the mind of the palpating person does not obstruct the unbiased perception, all EOs confirmed it and in doing so revealed that MI can be disturbing and limiting. But the statements of several EOs also showed solution paths when interacting with mental images which may have a distorting effect (e.g. openness, reflected interaction). That MI can also be distracting by its enormous "intensity" was shown in a statement of Interviewee8 (Experteninterviews $\backslash 08$ : 89 94). Interviewee4, Interviewee5, Interviewee6, Interviewee7 and Interviewee8 regarded adhering to anatomical visualisations as a source of disturbance and said that adhering to mental images might have a distracting effect on tactile perception. Interviewee2 saw MI as helpful but said that the tactile-haptic evaluation was the actual fundament and took on a critical attitude towards MI.

That MI of anatomical structures is the basis was confirmed by all EOs, even if in different graduations and with limitations. Especially Interviewee 5 emphasised that and expanded the view on palpation: "Anatomy should NOT invite over-familiarity" (Experteninterviews \05: 96 96). Statements of the majority of EOs should confirm this.

\section{DISCUSSION}

The study reveals that EOs use $\mathrm{MI}$ as a tool to support palpation. In this context, MI is used in different ways. The important and accompanying quality becomes apparent in the identification, 
recognition and comparison of anatomical conditions, in directing attention, in navigation and orientation.

The results also suggested that MI can be disturbing. In this context, it must be mentioned that there is also a distracting and deceiving component to MI, which obstructs the tactile perception and requires responsive strategies.
Finally, the study showed that MI is used situationally and becomes essential, e.g. in deep palpation. The results also showed that the imagery of EOs includes not only anatomical- physiological content but also other visualisations of any kind. In this context, different influencing factors could be identified that co-determine the visualisation capability, e.g. visualisation training.

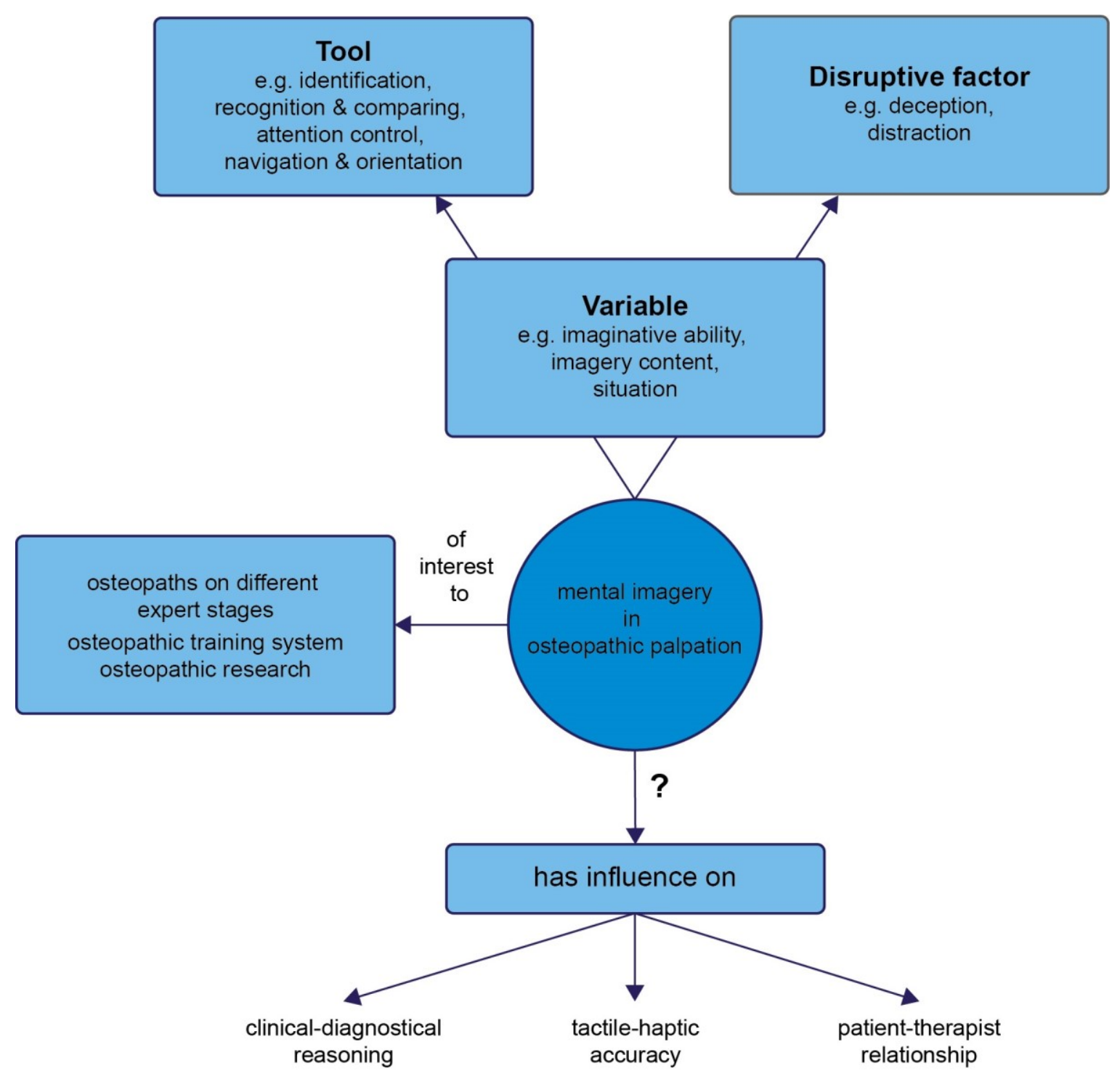

Figure 4. Overview about the role of $\mathrm{MI}$ in palpation, potential audience as well as limits of the study 
During palpation, osteopaths are faced with a variety of challenges (e.g. complexity and individuality of the human body; confrontation with the subdermal concealed areas). Given individual approaches and different levels of expertise, the research results should point out solution strategies to meet these challenges. In this context, the study can raise awareness for the importance of cognitive performances like MI. As the results suggest that the visualisation content of EOs can be disturbing and - for tactile perception - limiting, responsive and critical use seems to be even more significant.

The fact that anatomical-physiological images shape the MI of EOs shows the permanent importance and presence of the fundamental sciences in palpation and is reminiscent of, among others, osteopathic standards [14]. The results reveal the complexity of cognitive activities performed by osteopaths. Reciting biomedical facts is one thing; being able to retrieve, keep and use them as a mental image is another one. This, in particular, reminded of Still when he demanded from his students to be intimately familiar with form and function [15].

Whether the results can be transferred to osteopaths on the level of novices must be critically assessed. Still, the study shows that visualising is a capacity that develops over many years. The automatic retrieving of mental images, the temporary and targeted use of visualisation techniques as well as the detecting of tissue qualities during palpation is likely to be a challenge, especially for novice osteopaths. In the end, the study results show how EOs weight top-down processes in tactile perception. They underscore the position of authors like McConnell (1942, p. 363), who states: "It is through coordination of brain and [emphasis added] hand that the natures of both the normal and the abnormal body are sensed" [16]. This may also give young and learning osteopaths the opportunity to set their focus in palpation better.

This brings up the question to what extent the study results can influence the training system.
The awareness of MI, both as a tool and a disturbing factor might raise various questions. How can imaging form and function be trained? Do the mental images have a facilitating or inhibiting influence on the tactile-haptic detection of tissue? As lecturers play an essential role as tutors of imagination training, the results should be of interest for this target group.

Furthermore, the study results allow re-evaluating existing studies on the reliability of palpation. To regard MI as a possible reason for lack of reliability can be integrated into existing considerations and lead to a realignment of future research work.

In the end, the tactile-haptic accuracy is one of several factors for measuring palpation. To what extent MI leads to improvement of the perception performance can only be guessed. Even if statements by the EOs point in this direction, this study is not designed to measure the accuracy of palpation.

If the palpation is to be understood as building a relationship of trust and touching as a potentially co-creating factor of a successful patient-osteopath dyad [17], this study remains short of answers. Whether MI influences the quality of touching and being touched must be left open but can be the starting point of further research works.

Thinking and decision-making processes guide the diagnostic-therapeutical procedure. In this context, Esteves refers to the role of MI [18]. Even if this study, due to its design, cannot provide a statement about how MI affects the reasoning of EOs, it gives many insights, which should be followed upon.

Regarding the present study, there is room for improvement concerning certain aspects of the data analysis. Despite various recommendations in qualitative methodology [19], coding was done by the researcher alone. The option of consensual coding in the research team could not be used due to a lack of research funds and personnel resources. All the more important, however, were re-checks and responsive handling of data. 


\section{CONCLUSIONS}

Although findings from osteopathic literature and research could be supported, the knowledge about MI remains fragmentary. Therefore the research results can only be a piece of the puzzle to better understand the cognitive aspects in palpation. The study focuses on practical use, which should not be underestimated, but is still to be regarded as a pilot work. It forms the basis for other works to build on to explore the nature of MI in tactile perception. To also approach these complex processes scientifically, is a task, which is worth to be further pursued if you consider how vital palpation is in approaching the patient.

\section{Discloser}

The author has no personal financial or institutional interest in any of the materials or devices described in this article.

\section{Authors' contributions}

MMK provided substantial contributions to conception and design, acquisition of data, all analysis and interpretation of data;

JPB revised the article critically for relevant intellectual content. Both authors gave final approval of the version of the article to be published, and all authors agree to be accountable for all aspects of the work in ensuring that questions related to the accuracy or integrity of any part of the work are appropriately investigated and resolved.

\section{Author details}

${ }^{1}$ Praxis für Osteopathie, Burghausen, Germany

${ }^{2}$ Praxis für Osteopathie, Ettlingen, Germany

\section{Correspondence}

Mario M. Kraml MSc D.O.

Praxis für Osteopathie

Burg 9, 84489 Burghausen, Germany

e-Mail: mario.kraml@gmx.de
Received: 10 August 2019 Accepted: 28 October

2019 Published: 29 November 2019

\section{REFERENCES}

1. E. L. DiGiovanna, Palpation. In: E. L. DiGiovanna, S. Schiowitz, \& D. J. Dowling (eds.), An Osteopathic Approach to Diagnosis and Treatment. Philadelphia: Lippincott Williams \& Wilkins; 2005. p. 6466.

2. R. J. Hruby, Abdominal region. In: A. G. Chila (ed.), Foundations of Osteopathic Medicine. Philadelphia: Lippincott Williams \& Wilkins; 2011. p. 660668.

3. N. Sergueef, Cranial osteopathy for infants, children and adolescents. New York: Churchill Livingstone Elsevier; 2007.

4. S. M. Kosslyn, Image and Brain: The Resolution of the Imagery Debate. Cambridge, MA: MIT Press; 1996.

5. N. J. T. Thomas, Mental Imagery. Stanford Encyclopedia of Philosophy, 2016. Available: http://plato.stanford.edu/entries/mental-imagery/index.html\#MeaConMenIma [Accessed: July 16, 2016].

6. J. Pearson, C. W. Clifford, \& F. Tong, The functional impact of mental imagery on conscious perception. Current Biology. 2008; 18(13), p. 982-986. DOI: $10.1016 /$ j.cub.2008.05.048

7. S. J. Lederman, R. L. Klatzky, C. Chataway, \& C. D. Summers, Visual mediation and the haptic recognition of two-dimensional pictures of common objects. Perception \& Psychophysics. 1990; 47(1), p. 54-64. DOI: $10.3758 /$ bf03208164

8. K. Sathian, \& A. Zangaladze, Feeling with the mind's eye: the role of visual imagery in tactile perception. Optometry \& Vision Science. 2001; 78(5), p. 276-281. DOI: 10.1097/00006324200105000-00010

9. M. Zhang, V. D. Weisser, R. Stilla, S. C. Prather, \& K. Sathian, Multisensory cortical processing of object shape and its relation to mental imagery. Cognitive, Affective \& Behavioral Neuroscience. 2004; 4(2), p. 251-259. DOI: 10.3758/cabn.4.2.251

10. J. E. Esteves, Diagnostic palpation in osteopathic medicine: a putative neurocognitive model of expertise, 2011. Available: http://www.physio-education.com/wp- content/uploads/2016/03/abcg_Diagnostic_Palpation_in_osteopathic_medicinBookZZ.org_.pdf [Accessed: Feb. 15, 2014].

11. Aubin, K. Gagnon, \& C. Morin, The seven-step palpation method: A proposal to improve palpation 
skills. International Journal of Osteopathic Medicine. $2014 ; 17(1)$, p. 66-72.

https://doi.org/10.1016/j.ijosm.2013.02.001

12. J. E. Esteves, \& C. Spence, Developing competence in diagnostic palpation: Perspectives from neuroscience and education. International Journal of Osteopathic Medicine. 2014; 17(1), p. 52-60. https://doi.org/10.1016/j.ijosm.2013.07.001

13. U. Kuckartz, Qualitative Inhaltsanalyse. Methoden, Praxis, Computerunterstützung. Weinheim: Beltz Juventa; 2014.

14. General Osteopathic Council (GOsC). Standard 2000: Standard of proficiency, 2016. Available: http://www.osteopathy.org.uk/news-and-resources/document- library/publications/standard2000--standard-of-proficiency/ [Accessed: Feb. 20, 2016].

15. T. Still, The philosophy and mechanical principles of osteopathy. Kansas City, MO: Hudson-Kimberley Pub; 1902.

16. P. McConnell, Early days of Osteopathy. In: A. G. Hildreth (ed.), The lengthening shadow of $\mathrm{Dr}$ Andrew Taylor Still. Missouri: The Journal Printing Company; 1942. p. 357-369.

17. M. L. Elkiss, \& J. A. Jerome, Touch-More Than a Basic Science. The Journal of the American Osteopathic Association. 2012; 112(8), p. 514-517. PubMed

18. J. E. Esteves, Embodied clinical decision making in osteopathic manipulative medicine. American Academy of Osteopathy Journal. 2015; 25(2), p. 13-16. Researchgate

19. Ch. Schmidt, Analyse von Leitfadeninterviews. In: U. Flick, E. v. Kardorff, \& I. Steinke (eds.), Qualitative Forschung. Ein Handbuch. Reinbeck bei Hamburg: Rowohlt Taschenbuch Verlag; 2013. p. 252265.

\section{Rights and permissions}

This article is distributed under the terms of the Creative Commons Attribution 4.0 International License, which permits unrestricted use, distribution, and reproduction in any medium, provided you give appropriate credit to the original author(s) and the source, provide a link to the Creative Commons license, and indicate if changes were made. 